\title{
Advances in application of nanomaterials in remediation of heavy metal contaminated soil
}

\author{
Na Ding ${ }^{1}$, Mengxuan Han ${ }^{1}$, Yao He ${ }^{1}$, Xinshuai Wang ${ }^{1}$, Yuxuan Pan ${ }^{1}$, Hua Lin ${ }^{1}$, Guo Yu ${ }^{*}$ \\ ${ }^{1}$ Guangxi Key Laboratory of Environmental Pollution Control Theory and Technology, Guilin University of Technology, Guilin, China
}

\begin{abstract}
Soil heavy metal pollution has become an environmental problem that has attracted worldwide attention. Nanomaterials have the advantages of large specific surface area, strong adsorption capacity and high reactivity, making nanomaterials remediation technology an excellent application prospect in contaminated soil remediation. This article introduces the main classification of nanomaterials, summarizes the mechanism of nanomaterials to remove heavy metals, and the combination technology of nanomaterials. It provides a scientific reference for the further development of this field.
\end{abstract}

\section{1 introduction}

Soil heavy metal pollution is a worldwide environmental problem. The National Soil Pollution Survey Bulletin issued by the Ministry of Environmental Protection and the Ministry of Land and Resources shows that the soil environment in my country is not optimistic. Soil pollution in some areas is heavy, and the soil environmental problems in abandoned industrial and mining areas are more prominent. It includes cadmium, copper, arsenic, lead, chromium, zinc, nickel and other heavy metal pollution. After the soil is polluted by heavy metals, it will not only affect the yield and quality of crops, but also pass to the human body through the food chain. It has the potential to cause mutagenic, teratogenic and carcinogenic hazards to the human body, thereby endangering human health. Therefore, the remediation of heavy metal contaminated soil has always been the focus of environmental workers at home and abroad ${ }^{[1]}$. This article introduces the main classification of nanomateria-

ls, summarizes the mechanism of nanomaterials to remove heavy metals, and the combination technology of nanomaterials.

\section{The main classification of nanomaterials}

Nanomaterials refer to materials that have at least one dimension in the nanoscale range $(1-100 \mathrm{~nm})$ in a threedimensional space or are composed of them as basic units. When the particle size is on the order of nanometers, the quantum effect begins to affect the properties and structure of the substance, thus exhibiting superior physical and chemical properties compared with the macroscopic form ${ }^{[2]}$. There are many different classification methods for nanomaterials. According to the different geometric forms of nano materials, they can be divided into nano thin film materials, nano powder materials, nano fiber materials and nano bulk materials; according to their different functions, they can be divided into nano catalytic materials, nano biological materials, nano magnetic materials, nano thermal materials, etc. ${ }^{[3]}$. In the field of environmental remediation, it is often divided according to the material of nano materials, which can be divided into metal oxides (such as nano $\mathrm{TiO}_{2}$, etc.), nano clay minerals (such as nano kaolin, etc.), zero-valent metal materials (such as NZVI, etc.), and carbonaceous materials. Nano repair agents (such as single-walled carbon nanotubes, etc.) and semiconductor materials (such as various nanocrystalline materials, etc. $)^{[4]}$.

\subsection{Zero-valent metal nanomaterials}

Nano-zero-valent iron is easy to be oxidized, has high activity, and is a good reducing agent. Nano-zero-valent iron is nano-sized with a large specific surface area. It is magnetic and easy to separate. Although nano-zero-valent iron can efficiently remove heavy metals, it is easy to agglomerate, unstable, oxidize and cause second-ary pollution. Therefore, its development is limited. In order to overcome the above-mentioned problems, we start to add functional groups on the surface of nano-zero-valent iron or attach them to stabilizers for modification. One is to dope a second metal on the surface of nano-zero-valent iron to avoid surface oxidation. For example, Yan et al. ${ }^{[5]}$ doped Pd in nano-zero-valent iron to prevent its surface from being oxidized, so as to improve its activity. Second, we add stabilizers to the nano-zero-valent iron to prevent its agglomeration. For example, Kanel et al. ${ }^{[6]}$ used polyacrylic acid as a stabilizer to modify nano-zero-valent iron to improve the stability of nano-zero-valent iron.

\subsection{Carbonaceous nano-remediation agent}

Carbon nanotubes are one-dimensional carbon

*Corresponding author: yuguo@glut.edu.cn 
nanomaterials, mainly composed of carbon atoms arranged in a hexagonal shape to form one or several layers of coaxial tubes. Carbon nanotubes have a large specific surface, high optical density, high mesoporous and hollow structure, and the interaction between carbon nanotubes and pollutant molecules is very strong ${ }^{[7]}$. Li et al. ${ }^{[8]}$ found that carbon nanotubes treated with $\mathrm{H}_{2} \mathrm{O}_{2}$, $\mathrm{KMnO}_{4}$, and $\mathrm{HNO}_{3}$ can adsorb Cd (II) by 2-10 times that of untreated carbon nanotubes. There are more oxygencontaining functional groups on the surface of the tube.

\subsection{Nanometer metal oxide}

$\mathrm{TiO}_{2}$ is a typical n-type semiconductor. When $\mathrm{TiO}_{2}$ is irradiated with a wavelength of less than $385 \mathrm{~nm}$, the valence band electrons will be excited and will transition to the conduction band, so an electron $\left(\mathrm{e}^{-}\right)$-hole $\left(\mathrm{h}^{+}\right)$pair is formed, and the formed electron has reduction reaction can reduce heavy metal ions with high reduction potential. Holes have an oxidation reaction, which can oxidize organic pollutants non-selectively. In addition, when holes encounter water, they will produce strong oxidation of $\cdot \mathrm{OH}, \cdot \mathrm{OH}$ further interacts with pollutants oxidation occurs (for example, organic matter). $\mathrm{TiO}_{2}$ can also be used as an adsorbent to remove heavy metals in water. For example, Luo et al. ${ }^{[9]}$ studied the removal of arsenic from copper smelting wastewater by $\mathrm{TiO}_{2}$. The results show that the high adsorption capacity and chemical stability of $\mathrm{TiO}_{2}$ can reduce the concentration of heavy metals in sewage without generating sludge. The results apply to the global copper smelting industry. Maleki et al. [10] used polyamide-amine dendrimer modified $\mathrm{TiO}_{2}$ to adsorb and remove heavy gold in industrial wastewater. The research results show that the prepared adsorbent has a good adsorption effect on heavy metals in industrial sewage. After the modification of macromolecules, the adsorption sites are increased and the adsorption performance is improved.

\section{Mechanism of heavy metal removal by nanomaterials}

\subsection{Adsorption}

Nanomaterials have high adsorption efficiency due to their large specific surface area. The adsorption of heavy metals includes physical adsorption and chemical adsorption. Physical adsorption mainly refers to the adsorption of heavy metals by nanomaterials through intermolecular forces (such as van der Waals force, electrostatic attraction, etc.). For example, carbon nanotubes mainly fix heavy metal ions on the surface of carbon nanotubes through intermolecular forces such as van der Waals force and electrostatic attraction, so as to achieve the result of removing heavy metals ${ }^{[11]}$. Chemisorption is the adsorption by means of electron transfer or electron pair sharing to form chemical bonds or surface coordination compounds. The surface of nanomaterials that can chemically adsorb heavy metal ions often contains functional groups such as hydroxyl, amino, and carboxyl groups. These functional groups can form chelates with heavy metal ions, or can form ionic and covalent bonds with heavy metal ions to achieve the effect of removing heavy metals. Mallakpour et al. ${ }^{[12]}$ used polyvinyl alcohol (PVA) to modify the surface of $\alpha-\mathrm{MnO}_{2}$ to study the removal of $\mathrm{Cd}$ (II) in water. Because PVA contains hydroxyl groups, the hydroxyl groups can act as chelating sites to donate the lone pair of oxygen electrons. The $\mathrm{Cd}$ (II) metal ions thus form coordination bonds to achieve the purpose of removing $\mathrm{Cd}$ (II) in water.

\subsection{Redox}

The process of removing multivalent heavy metals with reducing nanomaterials is often accompanied by redox reactions. $\mathrm{Cr}$ (VI) is often reduced to $\mathrm{Cr}$ (III), which is less toxic. Nano-zero-valent iron is zero-valent, has high activity, and is a good reducing agent. Therefore, the mechanism of nano-zero-valent iron to remove heavy metal ions is not only adsorption but also reduction. Removal of contaminants by redox reaction, the most studied is NZVI. In general, NZVI can be used as an electron donor for reductive degradation or stabilization of contaminants. Many studies have used NZVI for reductive dechlorination of chlorinated organic contaminants (Such as PCBs and organochlorine pesticides) and for reductive conversion of high-value toxic metals ${ }^{[13-15]}$. In the structure of FeS, Fe (II) and S (-II) are used as electron donor to make $\mathrm{FeS}$ an important reducing agent and play an important role in the process of removing heavy metal ions.

\subsection{Co-precipitation}

The mechanism of heavy metal removal by nanomaterials is not only adsorption and redox but also Co-precipitation removal mechanism. Liu et al. ${ }^{[16]}$ synthesized a new type of nanomaterial with NZVI and $\mathrm{Mg}(\mathrm{OH})_{2}$ to remove $\mathrm{Pb}$ (II) from water. The study found that $\mathrm{Pb}$ (II) can form $\mathrm{Pb}(\mathrm{OH})_{2}$ with $\mathrm{OH}^{-}$, it can be removed by precipitation. NZVI can also be developed by adsorbing inorganic ions and coprecipitating with them (such as As (III)) ${ }^{[17]}$.

\section{Combination technology of nanomaterials}

In the remediation of heavy metal contaminated soil, it is often difficult to achieve the best remediation effect with a single remediation technology. Therefore, researchers have developed a variety of combined technologies to remediate heavy metals in the soil in order to achieve the best remediation effect. In addition to single use, nanomaterials will also be used in conjunction with other soil remediation technologies. The most typical ones include the combination of nanomaterials and phytoremediation technology, and the combination of nanomaterials and electric remediation technology. 


\subsection{The combination of nanomaterials and phytoremediation technology}

Phytoremediation technology decomposes, absorbs and extracts toxic and harmful substances in pollution carriers through terrestrial plants that grow in soil, solid sediments, sludge, and aquatic plants in water bodies such as rivers and lakes. The substance undergoes transformation and fixation, reducing its biological activity in the environmental carrier. The advantage of phytoremediation technology is that the soil structure and physical and chemical properties are not damaged during the restoration process. Phytoremediation of heavy metal contaminated soil is mainly carried out from four aspects: phytoextraction and remediation, plant volatilization remediation, phytostabilization remediation and plant rhizosphere filtration and remediation technology.

In this combination, Nanomaterials can play a role in the phytoremediation system by directly removing pollutants, promoting plant growth, and increasing the phyto-availability of pollutants. Nano-zero-valent iron (NZVI) is currently the most studied nanomaterial to promote phytoremediation. Nanomaterials can directly remove pollutants through adsorption or redox reactions. For example, carbon nanotubes can adsorb and fix pollutants (some hydrophobic organic pollutants). In the redox reaction to remove pollutants, NZVI can be used as an electron donor for reduction degradation or stabilize pollutants ${ }^{[18]}$. Nanomaterials can also increase the photosynthetic rate by promoting the absorption of water and nutrients, regulate the soil microbial community and reduce abiotic stress (such as high salinity and drought) to promote the growth of plants in the phytoremediation system. For example, the application of NHAP (Nano Hydroxyl Phosphate Lime) increases the fresh weight of ryegrass buds and roots, and promotes the growth of ryegrass. Its addition can increase the P content in the soil, promote plant growth, and increase biomass ${ }^{[19]}$. In addition, nanomaterials can act as a carrier of pollutants when entering cells, thereby improving bioavailability ${ }^{[20]}$.

\subsection{Combination of nanomaterials and electric repair technology}

The electric remediation technology of heavy metal contaminated soil is to apply a DC electric field at both ends of the contaminated soil. The heavy metal pollutants will migrate under a variety of migration mechanisms, and the soil will be discharged from the solution near the electrode. When the heavy metal content reaches a certain concentration, it can be removed. The electrolyte is discharged into the sewage tank for proper physical or conventional chemical treatment to realize the clean and remediation of contaminated soil. Electric repair technology is mainly a physical in-situ repair process, which has the advantages of less chemical treatment reagents, low energy consumption during the treatment process, and more thorough repair, and has received wide attention and applications. Recently, many researchers have proposed improved and enhanced technologies on the basis of electric repair technology. The comprehensive repair effect has made important progress and the application prospects are broader.

In this combined technology, nanomaterials can adsorb heavy metal ions in the soil, and enhance the transport potential of nanomaterials through electrophoresis, so that the advantages of the two technologies can be used to improve the effect of repairing soil heavy metal pollution. Some research reports found that electrokinetic processes can promote the diffusion and migration of nano-iron in coarse and medium-grained soils ${ }^{[21]}$. Further research has found that electrodialysis in the electrokinetic process in clayey soils can also increase the diffusion and migration of nano-iron ${ }^{[22]}$. Shariatmadari et al. (2009) used the combined technology of electric repair and permeable reactive barrier (the main material in the reactive wall is NZVI) to repair $\mathrm{Cr}$ contaminated soil. The results showed that the reduction of $\mathrm{Cr}(\mathrm{VI})$ in soil reached $88 \%$ by this combination technology, the total $\mathrm{Cr}$ removal reached 19\% [23].

\section{Conclusion}

The intensity of farmland land use in China is high and is strongly affected by human activities. Pollutants from industrial and mining enterprises, transportation, urbanization and public health defense, as well as pollution from agricultural production itself. The soil-crop system presents a complex situation of "coexistence of old and new pollutants and combined organic/inorganic pollution", especially the soil pollution caused by heavy metals and chlorinated persistent organic pollutants is more common. China's soil remediation industry is still in its initial stage, with personnel, technology and equipment still in the initial stage. The research and application of contaminated soil remediation technology are still in the experimental stage.

Nanomaterials have made more progress in the remediation of soil heavy metals, and they have shown good remediation effects. It has the characteristics of large specific surface area, strong adsorption capacity and high reactivity. It has great potential in soil heavy metal remediation. At present, most of the research on the application of nanomaterials to soil heavy metal remediation only stays in the exploration of the remediation efficiency and the effect of the soil environment. However, there is still a relatively lack of research on the mechanism of nanomaterials in the repair process, which will become a future research direction. Although nanomaterials have many advantages, the potential environmental risks of nanomaterials are poorly understood and difficult to quantify. The relationship between nanomaterials and microorganisms and whether they interfere with biological systems or even affect human health through food chain enrichment is still under study.

\section{Acknowledgment}

The authors thank the financial supports from the Guilin Science and Technology Project (20190219-3). 


\section{References}

1. Bolan, N., Kunhikrishnan, A., Thangarajan, R., et al. Remediation of Heavy Metal (Loid) s Contaminated Soil-To Mobilize or to Immobilize? J. Journal of Hazardous Materials, 266, 141-166(2014)

2. Gong X, Huang D, Liu Y, et al. Remediation of contaminated soils by biotechnology with nanomaterials: bio-behavior, applications, and perspectives. J. Critical reviews in biotechnology, 38(3), 455- 468(2018)

3. Yunliang Ji, Hongyu Liu. Characterization of nanomaterials and application of nanotechnology. J. Science and Technology of Western China (Academic), (07), 7-8+28(2007)

4. Meng Wang, Shibao Chen, Na Li, et al. Prospect of application of nanomaterials in contaminated soil remediation and sewage purification. J. Chinese Journal of Eco-Agriculture, 18(2), 434-439(2010)

5. Yan W, Herzing A A, Li X, et al. Structural evolution of Pd-doped nanoscale zero-valent iron (nZVI)in aqueous media and implications for particle aging and reactivity. J. Environmental Science \& Technology, 44(11), 4288-4294(2010)

6. Kanel S R, Goswami R R, Clement T P, et al. Two dimensional transport characteristics of surface stabilized zero-valent iron nanoparticlesin porous media. J. Environmental Science \& Technology, 42(3), 896-900(2007)

7. Abbas A, Al-amer A M, Laoui T, et al. Heavy metal removal from aqueous solution by advanced carbon nanotubes: Critical review of adsorption applications. J. Separation and Purification Technology, 157, 141-161(2016)

8. Li Y H, Wang S, Luan Z, et al. Adsorption of cadmium (II) from aqueous solution by surface oxidized carbon nanotubes. J. Carbon, 41(5), 51057-1062(2003)

9. Luo T, Cui J, Hu S, et al. Arsenic removal and recovery from copper smelting wastewater using $\mathrm{TiO}_{2}$. J. Environmental Science \& Technology, 44 (23), 9094-9098(2010)

10. Maleki A, Hayati B, Najafi F, et al. Heavy metal adsorption from industrial wastewater by PAMAM/ $\mathrm{TiO}_{2}$ nanohybrid: Preparation, characterization and adsorption studies. J. Journal of Molecular Liquids, 224, 95-104(2016)

11. Dandan Zhu, Qiixing Zhou. Research progress in the application of functional nanometerials in remediation of heavy metal polluted water bodies. J. Journal of Agro-Environment Science, 37(8), 15511564(2018)

12. Mallakpour S, Motirasoul F. Use of PVA/ $\alpha-\mathrm{MnO}_{2}-$ stearic acid nano-composite films prepared by sonochemical method as a potential sor-bent for adsorption of $\mathrm{Cd}$ (II) ion from aqueous solution. J. Ultrasonics Sonochemistry, 37, 623-633 (2017)

13. Di Palma, L. Gueye, M \& Petrucci, E. Hexavalent chromium reduction in contaminated soil: A comparison between ferrous sulphate and nanoscale zero-valent iron J. Journal of Hazardous Materials, 281, 70-76(2015)

14. El-Temsah Y S, Sevcu A, Bobcikova K, et al. DDT degradation efficiency and ecotoxicologycal effects of two types of nano-sized zero-valent iron (nZVI) in water and soil. J. Chemosphere, 144, 22212228(2016)

15. Huang D, Xue W, Zeng G, et al. Immobilization of Cd in river sediments by sodium alginate modified nanoscale zero-valent iron: Impact on enzyme activities and microbial community diversity. J. Water Research, 106, 15-25(2016)

16. Liu M, Wang Y, Chen L, et al. $\mathrm{Mg}(\mathrm{OH}) 2$ supported nanoscale zero valent iron enhancing the removal of $\mathrm{Pb}$ (II) from aqueous solution. J. ACS Applied Materials \& Interfaces, 7(15), 7961-7969 (2015)

17. Lackovic J A, Nikolaidis N P, et al. Inorganic arsenic removal by zero-valent iron. J. Environmen-tal Engineering Science, 17(1), 29-39(2000)

18. Deng Xiaopeng, Peng Kejian, Chen Yahua, et al. Absorption and enrichment of heavy metals in contaminated soil of mining areas by four solanaceae plants. J. Environmental Pollution and Prevention, 33(1), 59-64 (2011)

19. Ding L, Li J, Liu W, et al. Influence of nanohydroxyapatite on the metal bioavailability, plant metal accumulation and root exudates of ryegrass for phytoremediation in lead-polluted soil. J. International Journal of Environmental Research and Public Health, 14, 532 (2017)

20. Su Y, Yan X, Pu Y, Xiao F, et al. Risks of single-walled carbon nanotubes acting as contaminants-carriers: Potential release of phenanthrene in Japanese medaka (Oryzias latipes). J. Environmental Science \& Technology, 47, 4704-4710 (2013)

21. Dongmei Zhou, Changfen Deng. Research progress in electrokinetic remediation of heavy metal contaminated soil. J. Journal of Agro-Environment Science, 22(4),505-508(2003)

22. Chowdhury I, Cwiertny D M, Walker S L. Combined Factors Influencing the Aggregat- ion and Deposition of $\mathrm{Nano}_{-} \mathrm{TiO}_{2}$ in the Presence of Humic Acid and Bacteria. J. Environmental Science \& Technology, 46, 6968-6976(2012)

23. Gomes H I, Dias-Ferreira C, Ribeiro A B. Enhanced Transport and Transformation of Zero valent Nanoiron in Clay Using Direct Electric Current. J. Water, Air, \& Soil Pollution, 224(12),1-12(2013) 